\title{
EL RETORNO DE LA INOCUIZACIÓN. EL CASO DE LAS REACCIONES JURÍDICO-PENALES FRENTE A LOS DELINCUENTES SEXUALES VIOLENTOS*
}

\author{
Jesús-María Silva Sánchez \\ Catedrático de Derecho Penal \\ Universidad Pompeu Fabra
}

\section{Introducción.}

1.El término "inocuización" del delincuente nos suena a antiguo'. Su innegable vinculación al positivismo criminológico y su práctico abandono en la teoría de los fines del Derecho penal del último medio siglo, hace que no se encuentren apenas referencias al mismo en los textos que dan cuenta de la discusión continental europea al respecto. Ello, con independencia de la existencia, en mayor o menor medida, de instituciones como, por ejemplo, la "custodia de seguridad" (Sicherungsverwahrung) alemana, orientadas básica, aunque no exclusivamente (pues la dimensión resocializadora nunca se excluye de tales consecuencias jurídicas), a la inocuización de delincuentes habituales. Frente a ello, debe reconocerse, sin embargo, que la inocuización (incapacitation) nunca estuvo fuera de la discusión norteamericana en relación con los fines de la pena. Muy al contrario, al tratarse allí de un debate en el que la ponderación de costes y beneficios económicos ha desempeñado siempre un papel relevante, también ha subsistido la disposición a considerar argumentos que justificaran la utilidad de la inocuización de determinados grupos de delincuentes. En las últimas décadas, esta tendencia ha experimentado un auge considerable, a partir de dos fenómenos: uno, legislativo, la proliferación de las leyes "three strikes" ${ }^{2}$; el otro,

\footnotetext{
* Abreviaturas utilizadas. ACLR: American Criminal Law Review; AP: Actualidad penal; CLR: Cornell Law Review; MschrKrim: Monatsschrift für Kriminologie und Strafrechtsreform; NJW: Neue Juristische Wochenschrift; StV: Strafverteidiger; UPLR: University of Pittsburg Law Review; ZStW: Zeitschrift für die gesamte Strafrechtswissenschaft;

${ }^{1}$ Como es sabido, en von Liszt constituía uno de los tres fines de la "pena funcional" en términos preventivoespeciales (Zweckstrafe): la intimidación individual se dirigía al delincuente ocasional; la resocialización, al delincuente reiterado corregible; y la inocuización, al delincuente de estado incorregible. Cfr., por ejemplo, VON LISZT, Der Zweckgedanke mi Strafrecht (1882), en Strafrechtliche Vortrage und Aufsätze, I, Berlin 1905, pp. 126 y ss., 164 y ss., 166 y ss., con palabras durisimas: "Wie ein krankes Glied den ganzen Organismus vergiftet, so frisst der Krebsschaden des rapid zunehmenden Gewohnheitsverbrechertums sich immer tiefer in unser soziales Leben". Por tanto: "Gegen die unverbesserlichen muss die Gesellschaft sich schützen; und da wir köpfen und hängen nicht wollen und deportieren nicht können, so bleibt nur die Einsperrung auf Lebenszeit (bezw. auf unbestimmte Zeit)".
} 
doctrinal, la difusión de las teorías de la inocuización selectiva (selective incapacitation $)^{3}$.

2.De este modo, la inocuización del delincuente, si es que alguna vez abandonó la discusión norteamericana, lo que -como se ha indicado- es más que dudoso, ha vuelto a situarse en el centro de la discusión político-criminal de aquella cultura jurídica. A los fines aquí pretendidos, no es necesario profundizar en los aspectos que distinguen la orientación contemporánea a la inocuización de la que tuvo lugar en los Estados Unidos a principios de siglo. Baste una mención al respecto: por un lado, el grupo de los sujetos sobre los que básicamente se proyecta la pretensión inocuizadora es significativamente distinto ${ }^{4}$; por el otro,el método de la predicción de peligrosidad

${ }^{2}$ Sobre las leyes "three strikes" en Estados Unidos, que incorporan el conocido principio "three strikes and you're out", cfr. , de modo general, ROTMAN, "El concepto de prevención del delito", AP 43/1998, pp. 839 y ss., 854 y ss; GRASBERGER, "Three Strikes and You Are Out". Zu neuen Strafzumessungsansätzen bei Wiederholungstätern, ZStW 110 (1998), pp. 796 y ss.

${ }^{3}$ Cfr. GREENWOOD/ABRAHAMSE, Selective Incapacitation. Santa Monica 1982; un resumen de los criterios de Greenwood puede hallarse en VON HIRSCH/ ASHWORTH (ed.), Principled Sentencing. Boston 1992, p. 163. nota 5 .

La premisa mayor de la teoría de la inocuización selectiva es que resulta posible individualizar a un número relativamente pequeño de delincuentes (high risk offenders), respecto de los cuales cabe determinar que han sido responsables de la mayor parte de hechos delictivos y predecir que lo seguirán siendo. De modo que la inocuización de los mismos -esto es, su retención en prisión el máximo tiempo posible- conseguiría una radical reducción del número de hechos delictivos y, con ello, importantes beneficios al menor coste. Expresado en términos contables: recluir 2 años a cinco delincuentes cuya tasa predecible de delincuencia es de 4 delitos por año, "ahorra" a la sociedad 40 delitos y le cuesta 10 años de prisión. En cambio, si esos mismos diez años de prisión se emplean en recluir 5 años a dos delincuentes cuya tasa predecible de delincuencia es de 20 delitos por año, el "ahorro" social es de 200 delitos; y así sucesivamente. Con ello, la "selective incapacitation" muestra significativas ventajas económicas frente a la indiscriminada, o ciega, "general incapacitation".

Evidentemente, la teoría de la inocuización selectiva plantea-como, en general, las tesis inocuizadoras- problemas de fundamentación empirica, por un lado, y de legitimación axiológica (proporcionalidad), por el otro. Sobre el debate al respecto, cfr. BLACKMORE/ WELSH. "Selective Incapacitacion: Sentencing According to Risk", en Crime \& Delinquency, October 1983, pp. 504 y ss,; también, los trabajos de WILSON, VON HIRSCHY TONRY, en VON HIRSCH/ ASHWORTH (ed.). Principled Sentencing, pp. 148 y ss., 158 y ss., 165 y ss. En lengua castellana, es excelente el análisis de OTTAVIANO, "Selective Incapacitation". El retorno de la inocuización al pensamiento penal norteamericano contemporáneo, Prudentia luris (Revista de la Facultad de Derecho y Ciencias Políticas de la Pontificia Universidad Católica Argentina "Santa María de los Buenos Aires") 49, mayo 1999, pp. 137 y ss., especialmente 150 y ss., 154-155.

${ }^{4}$ En su día éstos habian sido básicamente delincuentes habituales contra la propiedad; ahora, en cambio, son delincuentes violentos. Por otro lado, se señala que la base ideológica del recurso a tales métodos también ha cambiado; a principios de siglo, se justificaba desde perspectivas de Estado social, mientras que ahora se trata de un enfoque neoliberal. En fin, el método de abordaje de la cuestión de la peligrosidad se ha visto sustancialmente modificado. Sobre estos extremos, cfr. la exposición de PRATT, "Dangerousness, Risk and Technologies of Power", en Australian and New Zealand Journal of Criminology, 28, 1995, pp. 3 y s5; El mismo, "Governing the Dangerous: an Historical Overview of Dangerous Offender Legislation", en Social \& Legal Studies 5 (1996), pp. 21 y ss. 
para determinar los sujetos que, precisamente, han de ser inocuizados, también ha cambiado radicalmente ${ }^{5}$.

3. Sea como fuere, mi opinión es que el fenómeno no es casual. Por el contrario, el "retorno" de la inocuización se halla en perfecta sintonía con la evolución ideológica general de la Política criminal; y no sólo de la Política criminal norteamericana. En dicha evolución cabe advertir varios elementos determinantes. Así, a mero título de ejemplo, por un lado, el creciente desencanto, fundado o no, en torno a las posibilidades de una intervención resocializadora del Estado sobre el delincuente ${ }^{6}$. $Y$ por otro lado, la elevadísima sensibilidad al riesgo y la obsesión por la seguridad que muestran amplios grupos sociales ${ }^{7}$. Así, parece estar sentada la base ideológica de los planteamientos inocuizadores. Uno de los más significativos es el que se refiere al ámbito, especialmente sensible, de los delincuentes sexuales ${ }^{8}$. En lo que sigue, se trata de examinar cómo las tesis de la inocuización se han ido desarrollando en dicho ámbito en la reciente legislación norteamericana y, también, aunque en menor medida, en la alemana.

${ }^{5}$ Los métodos predictivos basados en el análisis psicológico individual de responsabilidad o peligrosidad han sido sustituidos por otros de naturaleza actuaria (actuarial justice), de modo que el delito pasa a ser abordado con las mismas técnicas probabilísticas y cuantitativas que, en el ámbito de los seguros, por ejemplo, se utilizan para la gestión de riesgos. Ello supone recurrir al método estadístico, tomando como base determinados indicadores, cuya cuantificación es el punto de partida para emitir pronósticos de peligrosidad sobre grupos o clases de sujetos, sin necesidad de entrar en estudios de la psicología del individuo concreto. Sobre esta noción, en la que se basa la llamada, en los Estados Unidos, "New Penology", existe ya una muy extensa bibliografía. Cfr., por ejemplo, REICHMAN, "Managing Crime Risks: Toward an Insurance Based Model of Social Control", en Research in Law, Deviance and Social Control, 8, 1986, pp. 151 y ss.; FEELEY/SIMON, "The New Penology: Notes on the Emerging Strategy of Corrections and Its Implications". Criminology, vol. 30, n² 4, 1992, pp. 449 y ss.: FEELEY/SIMON, "Actuarial Justice:The Emerging New Criminal Law", en NELKEN (ed.), The Futures of Criminology, London 1994, pp. 173 y ss.; Ottaviano, Prudentia luris 49, pp, 146-147.

${ }^{6}$ Un desencanto que es ideológico, pero no sólo ideológico. Quiere indicarse con ello que también es posible que influya la voluntad de reducir las inversiones en tratamientos de resocialización (lo que explica, por ejemplo, el que nunca llegaran a implantarse en Alemania los establecimientos de terapia social previstos en la reforma penal de aquel país de los años sesenta y setenta). Tal reducción de inversión en el ámbito penitenciario es coherente con la reducción del gasto público propia de la crisis de los Estados del bienestar. Claro es que se pensará que la inversión en resocialización es eficiente, en el sentido de que, al menos a medio plazo, reduce los costes sociales derivados de la comisión de delitos. Pero los análisis a medio plazo no siempre son propios de la política de gestión de la crisis, a la que asistimos.

${ }^{7}$ De ello me he ocupado en mi libro La expansión del Derecho penal. Aspectos de la política criminal en las sociedades postindustriales, Madrid 1999, al que me permito remitir en este punto.

${ }^{8}$ Es discutible que la evidente sensibilidad social ante este grupo de delitos se corresponda con un incremento real de su producción, así como con la existencia en ellos de tasas de reincidencia superiores al común de los delitos. Cfr. ROSENAU, "Tendenzen und Gründe der Reform des Sexualstrafrechts", StV 1999, pp. 388 y ss., p. 390, donde se pone de manifiesto que en la última década las cifras permanecen esencialmente constantes; y p. 392, donde se pone de manifiesto que la tasa de reincidencia es ciertamente elevada pero no sustancialmente distinta de la general. Cfr. asimismo el informe de SCHALL/SCHREIBAUER, "Prognose und Rückfall bei Sexualstraftätern". NJW 1997, pp. 2412 y ss., 2413. 


\section{La evolución de la Política criminal norteamericana en las reacciones frente a los delincuentes sexuales violentos.}

1. Hasta los años setenta y ochenta, el mecanismo más significativo de intervención sobre los delincuentes sexuales imputables peligrosos en Estados Unidos era el llamado "civil commitment", esto es, su internamiento indeterminado en centros psiquiátricos con fines de tratamiento. Esta fue, en efecto, la línea que abonaban las llamadas "Sexual Psycopath Acts" (leyes de "psicópatas sexuales")y que, como se advierte, conducían a una sustancial equiparación de los sujetos imputables estimados peligrosos con los inimputables, asimismo peligrosos. Sin embargo, lo cierto es que las referidas disposiciones sufrieron crítica tanto desde las perspectivas garantistas, como desde las defensistas. Así, desde las primeras, se manifestaba que el hecho de que a tales sujetos, mentalmente no enfermos, se les sometiera supuestamente a tratamiento psiquiátrico, suponía una incongruencia. Además, se objetaba que los psiquiatras implicados en tales instituciones tendían a mantener su diagnóstico de peligrosidad (overpredicting dangerousness), para no correr el riesgo de que tuvieran lugar nuevos delitos tras la concesión de la libertad al delincuente 9 . De este modo, lo cierto era que la duración del internamiento psiquiátrico indeterminado podía acabar siendo vitalicia y de hecho lo era en la gran mayoría de los casos - ${ }^{10}$. Estas y otras consideraciones condujeron al progresivo abandono de la referida orientación, avalada, además, finalmente por la sentencia del Tribunal Supremo recaída en el caso Foucha vs. Louisiana $^{11}$. Pero lo significativo es que las consideraciones garantistas tenían, en su oposición al "civil commitment", el insospechado apoyo de las tesis más defensistas. Así, desde esta otra perspectiva, se había criticado el estado de cosas vigente, manifestando el temor de que los delincuentes sexuales pudieran eludir duras condenas de prisión en virtud de un internamiento, que se sospechaba breve ${ }^{12}$, en centros de tratamiento, que además habían de resultar - en opinión de los críticos - en general inefectivos ${ }^{13}$.

2. Como consecuencia de lo anterior, en los años noventa se empieza a difundir un modelo legislativo distinto, que expresa de modo claro el abandono de la anterior

${ }^{9}$ Cfr. ALEXANDER, "The Civil Commitment of Sex Offenders in Light of Foucha vs. Louisiana", en Criminal Justice and Behavior, vol. 20, $\mathrm{n}^{2} 4$, December 1993, pp. 371 y ss.,

${ }^{10}$ HORWITZ, "Sexual Psycopath Legislation: Is There Anywhere to Go but Backwards?" , UPLR 57 (1995), pp. 35 y ss., 45.

11 Supreme Court of the United States, Terry Foucha, petitioner vs. Louisiana (18 de mayo de 1992).

${ }^{12}$ Pues, de hecho, bastaría con que los psiquiatras responsables del centro en cuestión revocaran el pronóstico de peligrosidad para que el sujeto quedara en libertad. Claro es que esta hipótesis, como se ha indicado, no era muy realista, pues los referidos psiquiatras, aunque sólo fuera para eludir cualquier responsabilidad en caso de nueva comisión de hechos delictivos tras la puesta en libertad, tendían a mantener de modo permanente el pronóstico de peligrosidad.

${ }^{13}$ HORWITZ, UPLR 57 (1995), p. 47. 
orientación (pretendidamente) terapéutica y la acogida de una línea claramente punitivista e inocuizadora ${ }^{14}$. Esta línea, iniciada por la "Sexually Violent Predators Act" del Estado de Washington (1990) $)^{15}$, se va extendiendo a lo largo de la última década por un gran número de estados norteamericanos. La estructura del nuevo modelo de consecuencias jurídicas para delincuentes sexuales violentos es, de nuevo, muy sencilla: si el delincuente es estimado peligroso, tras el cumplimiento de la pena se le impone una medida de seguridad acumulativa de inocuización ${ }^{16}$. No se trata, pues, de la imposición de una "medida de seguridad" en lugar de la pena, sino de su imposición después de la pena ${ }^{17}$. No es necesario que se constate una situación de habitualidad o, al menos, una reincidencia de pasado. Los únicos requisitos son que se trate del autor de un delito sexual violento; que haya afectado, al menos, a dos víctimas; y que exista un pronóstico de reincidencia futura.

3. Como se ha indicado, este modelo se diferencia del anterior en que separa claramente la pena de la medida de seguridad posterior. Así, un modelo de internamiento indeterminado (en principio, orientado en términos resocializadores, pero con una importante dimensión inocuizadora) se ve sustituido por una pena regida por el principio de proporcionalidad, a la que se suma una medida regida por el principio de inocuización ${ }^{18}$. Expresado en términos de nuestra discusión: se trata de un sistema dualista, con ejecución de la medida con posterioridad a la pena y duración indeterminada de aquélla ${ }^{19}$. Ciertamente, resulta difícil no identificar en el tránsito de un modelo al otro el paso de una ideología terapéutica a una ideología neoclásica de "just deserts" a la que, en la lógica de los movimientos defensistas de "law and order", se le suman elementos adicionales de inocuización ${ }^{20}$

4. El cambio conceptual no dejaba de implicar, sin embargo, el mantenimiento de las mismas tensiones garantistas que, en su día, dieron lugar a que se dictara la

\footnotetext{
${ }^{14}$ El giro ha sido estudiado y expresado con claridad y concisión por HORWITZ, UPLR 57 (1995), pp. 40 y ss.; WALTHER, "Umgang mit Sexualstraftätern: Amerika, Quo Vadis? Vergewisserungen über aktuelle Grundfragen an das (deutsche) Strafrecht", MschrKrim 80 (1997), pp. 199 y ss., 205 y ss.

15 Un detallado análisis en GREENLEES, "Washington State's Sexually Violent Predators Act: Model or Mistake", ACLR 29 (1991), pp. 107 y ss. Sobre su origen coyuntural, en un clima de conmoción pública, GREENLEES, ACLR 29 (1991), pp. 108-110; HORWITZ, UPLR 57 (1995), p. 48-49.

${ }^{16}$ Cfr. HORWITZ, UPLR 57 (1995), p. 37.

${ }^{17}$ Cfr. GREENLEES, ACLR 29 (1991), p. 110 .

${ }^{18}$ Sobre el papel prácticamente nulo de la reinserción, que, por otro lado, se ve muy dificultada por el hecho de que la medida se cumpla con posterioridad a la pena, HORWITZ, UPLR 57 (1995), pp. 55-56.

${ }^{19}$ Con claridad, HORWITZ, UPLR 57 (1995), p. 50.

${ }^{20}$ HORWITZ, UPLR 57 (1995), p. 62: "As the public began to cry out for longer sentences for convicted criminals, criminologists began to focus on the retributive and incapacitative aspects of criminal punishment, abandoning much serious discussion of rehabilitation and deterrence"; y p. 64: "By the 1990s, incapacitation had emerged as 'the principal justification for imprisonment in American criminal justice".
} 
sentencia Foucha vs. Louisiana ${ }^{21}$. En efecto, en el plano empírico la nueva legislación también ha de afrontar el problema de las dificultades en la predicción de la peligrosidad o de la reincidencia, sobre todo cuando el sujeto tan sólo ha realizado un hecho delictivo ${ }^{22} . Y$, en el plano valorativo, la vaguedad de los términos de la ley determina que sea muy complejo determinar con precisión en qué casos debe procederse a imponer el internamiento una vez cumplida la pena ${ }^{23}$. Así pues, las dudas sobre la constitucionalidad del modelo están seriamente fundadas ${ }^{24}$.

5. Por lo demás, el sistema dualista que se acaba de reseñar se completa con una serie de medidas adicionales, todas ellas ordenadas a garantizar la neutralización del delincuente, esto es, a asegurar que el mismo no volverá a ser fuente de riesgos para la comunidad. En esta línea se mueven, en primer lugar, las medidas de supervisión y control posteriores al cumplimiento de la condena (supervised release, parole) y establecidas en la propia sentencia. Con ellas se pretende mantener bajo control el momento, especialmente delicado, de reintegración en la sociedad del delincuente; pero no puede ignorarse que en algunos estados tienen una duración perpetua. Asimismo, en segundo lugar, la aplicación, durante el período de ejecución de la pena privativa de libertad, de tratamientos hormonales, convencionalmente denominados "castración química" ${ }^{25}$. En tercer lugar, los deberes de registro de ex-delincuentes sexuales, en ocasiones asimismo de duración vitalicia, y que fueron introducidos en la Jacob Wetterling Crimes Against Children and Sexually Violent Offender Registration $\mathrm{Act}^{26}$.

${ }^{21}$ Lo subraya WALTHER, MschrKrim 80 (1997), p. 207.

${ }^{22}$ Cfr. GREENLEES, ACLR 29 (1991), pp. 111 y ss., 116: "The result will be lifetime commitment for most, if not all, individuals labeled as sexually violent predators".

${ }^{23}$ Entre otros aspectos, cfr. GREENLEES, ACLR 29 (1991), pp. 121 y ss. Cfr. también, de modo general, BERG, "Give me Liberty or Give me Silence: Taking a Stand on Fifth Amendment Implications for Court-ordered Therapy Programs", CLR 79 (1994), pp. 700 y ss

${ }^{24}$ Trata de proponer un modelo legislativo más garantista, dentro del propio esquema de las leyes actualmente vigentes, HORWITZ, UPLR 57 (1995), pp. 66 y ss. Sus caracteristicas serían la exigencia de condena previa, el juicio cualificado de peligrosidad establecido por ley, una cierta proporcionalidad (duración máxima y relación con el delito cometido), etc.

${ }^{25}$ Estos tratamientos, que en principio son opcionales, pueden llegar a ser obligatorios en caso de reincidencia. Cfr. la descripción y análisis, en términos básicamente escépticos de HICKS, "Castration of Sexual Offenders. Legal and Ethical Issues", en The Journal of Legal Medicine 1993, pp. 641 y ss. Con todo, debe subrayarse que los tratamientos hormonales parecen ganar adeptos entre los políticos. Asi, el diario EL PAÍS de 1 de septiembre de 1999 da cuenta de que el Partido Popular austríaco (OVP) propone, en su programa de Política criminal, la castración química de los autores de delitos sexuales contra niños, como requisito de su excarcelación al final del cumplimiento de la condena de prisión.

${ }^{26}$ La "Jakob Wetterling Act" fue introducida en 1994, como parte de la "Violent Crime Control and Law Enforcement Act". Cfr. un análisis detallado de las características y problemas constitucionales de esta ley en LEWIS, "The Jacob Wetterling Crimes Against Children and Sexually Violent Offender Registration Act: An Unconstitutional Deprivation of the Right to Privacy and Substantive Due Process", en Harvard Civil Rights-Civil Liberties Law Review 31 (1996), pp, 89 y ss. La cuestión fundamental la describe correctamente en los siguientes términos: "At the core of the debate over sex offender laws lies a fundamental tension between the desire to protect society -especially children-from perceived or actual recidivists and the constitutional obligation to 
A partir de esta ley, en efecto, los diversos estados de la Unión tienen la obligación de dictar leyes que, a su vez, impongan a los penados por delitos sexuales violentos o realizados sobre menores el deber de inscribirse en los correspondientes registros públicos ${ }^{27}$. Por fin, en la misma línea se mueve el "Community Empowerment" (o Community Notification $)^{28}$, esto es, el sistema de notificación a una determinada comunidad (el vecindario en el que vive el sujeto) de los datos obtenidos en virtud del deber de registro ${ }^{29}$. El conjunto de medidas resulta enormemente revelador de los extremos a los que puede llegar la supuesta lógica de la "seguridad colectiva", a la hora de restringir derechos individuales y estigmatizar al sujeto ${ }^{30}$.

\section{Aspectos de la nueva política criminal alemana en materia de delincuentes sexuales} peligrosos. La "Gesetz zur Bekämpfung von Sexualdelikten und anderen gefärlichen Straftaten" de 26 de enero de 1998.

1. Lo anterior podría ser visto con distancia como mera manifestación de la siempre peculiar política criminal norteamericana; pero, aunque así fuera, el juicio pecaría de temerario, al minusvalorar la enorme influencia que dicho modelo acaba teniendo en todo el mundo, y en particular en Europa, como consecuencia de la universalización de los patrones culturales del "American Way of Life". Sin embargo, lo cierto es que la Política criminal europea, si bien desde luego no alcanza los extremos descritos para la norteamericana, empieza a mostrar rasgos significativos en esa misma

protect the basic rights and liberties of all members of society, particularly the rights and liberties of those whom society despises" (p. 90).

${ }^{27}$ Una de las más conocidas es la de New Jersey, la Sexual Offender Registration Act de 1994, conocida como "Megan's Law", en memoria de una niña asesinada. Cfr., al respecto, LEWIS, Harvard Civil Rights - Civil Liberties Law Review 31 (1996), pp. 114 y ss. Un examen del problema desde una perspectiva general en HEBENTON/THOMAS, "Sexual Offenders in the Community: Reflections on Problems of Law, Community and Risk Management in the U.S.A., England and Wales", en International Journal of the Sociology of Law, 24, 1996, pp. 427 y ss.

Estas disposiciones han tenido eco en la prensa europea, española en particular, al advertirse la posibilidad de acceder a través de internet a fichas de delincuentes sexuales que ya cumplieron su condena, en las que se da cuenta de todo tipo de datos personales de los mismos. Por lo demás, el criterio parece que trasciende del ámbito de los delincuentes sexuales. En este sentido, el diario LA VANGUARDIA de 27 de octubre de 1999 da cuenta de la decisión del alcalde de Manchester de publicar nombre, apellidos, dirección y fotografía de delincuentes, ya juzgados e incluso que ya hayan cumplido condena, en su día descubiertos en flagrante delito por las cámaras de circuito cerrado instaladas en el centro de la ciudad. El argumento: "...la inmensa mayoría de los ciudadanos de Manchester respetan la ley y pagan sus impuestos y tienen derecho a conocer los nombres y apellidos de quienes ponen en peligro su bienestar y seguridad, y no aceptan las reglas del juego".

${ }^{28}$ También prevista en la Jakob Wetterling Act.

${ }^{29}$ Sobre todo ello, con referencias, WALTHER, MschrKrim 80 (1997), pp. 209 y ss, crítica en pp. 217 y ss.

${ }^{30}$ En efecto, la cuestión, vista desde la perspectiva de los derechos individuales, es si el delincuente que ha cumplido su condena no tiene un derecho a la privacidad sobre los hechos que dieron lugar a la misma. Expresado de otro modo, si acaso el Estado podría declarar ilimitado el período de vigencia de los antecedentes penales, así como hacerlos públicos. 
dirección ${ }^{31}$. Baste, para ejemplificarlo, la referencia a la legislación vigente en Alemania desde 1998 en materia de reacciones frente a los delincuentes sexuales ${ }^{32}$. Su leit motiv es, como en el caso norteamericano, la maximización de la idea de seguridad ${ }^{33}$, aunque, a diferencia de lo que sucede en aquel país, no se abandona la dimensión resocializadora del tratamiento. Esta idea rectora conduce reducir los requisitos de la "custodia de seguridad" (Sicherheitsverwahrung), consecuencia jurídica (medida posterior a la pena) no limitada por el principio de culpabilidad, sino por consideraciones de eliminación de la peligrosidad, aun cuando no se excluya el tratamiento. La pretensión de esta reducción es doble: de una parte, desvincular a la institución de su ligamen tradicional con la habitualidad, o a la sucesión de hechos delictivos ${ }^{34}$, de manera que, en la nueva regulación, es posible imponerla ya con ocasión de la primera condena del sujeto; de otra parte, eliminar su ya limitada vinculación con un criterio de proporcionalidad, al ser posible su duración indeterminada (más allá del límite de los diez años de duración que preveía el régimen derogado) en casos de que exista un riesgo de violencia $(\S 66, \text { III StGB })^{35}$. Por lo demás, en la misma línea inciden las nuevas disposiciones relativas a la libertad vigilada (vigilancia de conducta, Führungsaufsicht), que se pueden adoptar en la fase de tránsito hacia la plena

${ }^{31}$ Hasta el momento, en Europa se detectan desde luego tan sólo cambios de alcance más limitado que el modelo norteamericano. Asi, en Gran Bretaña en la Crime (Sentences) Act de 1 de octubre de 1997, se establece una reclusión a perpetuidad para el caso de un segundo delito grave (por ejemplo, agresión sexual a un menor), de la que sólo se puede prescindir en el caso de ausencia total de peligrosidad del sujeto, y que, en la práctica viene a corresponder a la custodia de seguridad. En Francia, por su parte, la Loi $n^{2} 98-468$ de prevención y represión de delitos sexuales así como de protección de menores tiene como novedad más importante la previsión una nueva pena accesoria, posterior al cumplimiento de la condena, de tratamiento socio-terapéutico bajo supervisión judicial, asi como la posible imposición de otras medidas (arts. 131-36-1 y ss Code pénal). Por tanto, la orientación parece atribuir prioridad al tratamiento sobre la inocuización. En Italia, en lo que alcanzo a ver, la situación sigue siendo la clásica (arts. 199 y ss. del Codice penale), de modo que los delincuentes sexuales peligrosos pueden ser sometidos a una medida de seguridad posterior al cumplimiento de la pena, sin que, al parecer, exista institución alguna que esté orientada de modo expreso a la reinserción de los mismos. El caso español es conocido: no existen medidas de inocuización de delincuentes sexuales imputables y peligrosos para después del cumplimiento de la pena; es más, los propios delincuentes sexuales inimputables se someten (como los demás inimputables) a una medida sujeta al estricto principio de proporcionalidad con el hecho. Tampoco existen medidas especificas de tratamiento más allá de las propias del tratamiento penitenciario; en concreto, no existen medidas de tratamiento obligatorio para la fase de la libertad condicional ni tampoco para el momento posterior al licenciamiento definitivo del penado.

32 Sobre sus rasgos esenciales, $\mathrm{SCHÖCH}$, "Das Gesetz zur Bekämpfung von Sexualdelikten und anderen gefährlichen Straftaten vom 26.1.1998". NJW 1998, pp. 1257 y ss.; ROSENAU, StV 1999, pp. 393 y 55.

${ }^{33}$ Su causa próxima se halla, según todos los indicios, en el impacto producido en la sociedad alemana por tres casos de muertes de niños a manos de delincuentes sexuales; SCHÖCH, NJW 1998, pp. 1257 y ss.

${ }^{34}$ No hay que olvidar que la custodia de seguridad se estimaba tradicionalmente como una de los últimos recursos de necesidad de la política criminal: ROSENAU, StV 1999, p. 396. La mayor flexibilidad que establece la nueva regulación para la imposición de consecuencias jurídicas asegurativas o inocuizadoras se estima vulneratoria del principio de proporcionalidad por BOETTICHER, "Der neue Umgang mit Sexualstraftätern -eine Zwischenbilanz", MschrKrim 81 (1998), pp. 354 y ss., 364-365.

${ }^{35} \mathrm{Cfr}$. una referencia a la polémica que ha rodeado la introducción de esta nueva regulación, con una valoración favorable, en SCHÖCH, NJW 1998, pp.1261-1262. 
libertad(§ 68 StGB) y cuya duración, de dos a cinco años, puede también convertirse en indeterminada si no se cumplen las instrucciones que se establezcan y puede constatarse, por otro lado, la persistencia de peligro.

2. La propia lógica de la seguridad conduce a restringir las posibilidades de aplicación de ciertas medidas de flexibilización de las reacciones jurídico-penales, que tradicionalmente se habían inspirado en criterios de resocialización ${ }^{36}$ (así, por ejemplo, la libertad condicional $)^{37}$. O , en todo caso, a condicionar la concesión de la libertad condicional o de la libertad vigilada a la aceptación de un tratamiento terapéutico ${ }^{38}$. Otras disposiciones de carácter, éstas sí, directamente resocializador son las contenidas en la reforma del $\S 9$ de la Ley Penitenciaria (Strafvollzugsgesetz), relativas al ingreso de penados -y en el marco del cumplimiento ordinario de la condena- en instituciones de terapia social, siempre que sean susceptibles de tratamiento.

3. El modelo tiene una base ideológica muy clara: la sociedad, incluso en el caso de ciertos delincuentes no habituales, cuyo delito haya tenido, sin embargo, una especial incidencia, por el número de víctimas, por ejemplo, renuncia a asumir porcentaje alguno del riesgo de reincidencia. Todo el riesgo se hace recaer sobre el autor, quien de este modo es sometido a intervenciones asegurativas de la máxima intensidad. La adecuación de este modelo al principio de proporcionalidad resulta más que discutible $e^{39}$.

\section{Perspectivas.}

1. El debate acerca de las consecuencias jurídicas específicas de la sociedad de la inseguridad no ha hecho, probablemente, más que empezar ${ }^{40}$. El ámbito, especialmente sensible, de los delincuentes sexuales, no es, en este punto, sino la punta del "iceberg". Lo que, en todo caso, parece obvio es que la absolutización de la seguridad como objetivo político-criminal conduce a la reconstrucción de un Derecho de la peligrosidad. Expresado de otro modo; se vuelve a replantear, para sujetos imputables, el recurso a medios de aseguramiento cognitivo, junto a la pena como mecanismo de

\footnotetext{
${ }^{36}$ Un informe de expertos sobre el modo de proceder con tales delincuentes es el titulado "Sexualstraftäter im Massregelvollzug -Grundfragen ihrer therapeutischen Behandlung und der Sicherheit der Allegemeinheit"-, en MschrKrim 79 (1996), pp. 147 y ss.

${ }^{37} \mathrm{Cfr}$. SCHÖCH, NJW 1998, pp. 1258 y ss

${ }^{38}$ SCHÖCH, NJW 1998, p. 1260.

${ }^{39}$ Críticamente, Deutsche Gesellschaft für Sexualforschung. Stellungnahme zum "Gesetz zur Bekämpfung von Sexualdelikten", MschrKrim 81 (1998), pp. 368 y ss

${ }^{40}$ Para el caso de los delincuentes sexuales, señala HORWITZ, UPLR 57 (1995), p. 66: "t. it seems highly probable that the trend towards the reenactment or greater use of sexual psycopath statutes will continue in an anabated fashion".
} 
aseguramiento contrafáctico de la vigencia de la norma. No en vano, en la reciente discusión político-criminal británica, el objeto del debate se centra ya en si debe o no esperarse a la producción de un hecho lesivo para proceder a arbitrar una reacción, cuando resulta que existen las bases para formular un juicio de peligrosidad ${ }^{41}$. Esto es, se ha reabierto incluso el debate en torno a las reacciones predelictuales, llámense éstas medidas de seguridad o no.

2.Esta situación obliga, según creo, a analizar de nuevo -lo que parecía definitivamente superado- si el principio de peligrosidad puede legitimar realmente (y hasta qué punto) una intervención restrictiva de derechos sobre el sujeto activo. En la discusión sobre el nuevo Derecho de la peligrosidad (postdelictual o no), lo importante, en mi opinión, es advertir y valorar el hecho de que el mismo se concibe como derecho de estricta seguridad frente al futuro (puramente preventivo) y no de respuesta frente al pasado. En cambio, estimo menos relevante la cuestión relativa a la etiqueta de las reacciones cognitivas que se establezcan: civiles ("civil commitment" ha sido su denominación en los Estados Unidos), penales o administrativas. Esta cuestión de la etiqueta de la reacción (no se olvide: cognitiva) ha enzarzado, en cambio, a la doctrina española en los últimos años, y acabó influyendo sobre el Código de $1995^{42}$.

3. Lo cierto es que, en el caso de los inimputables, el principio de peligrosidad evidentemente sí legitima la restricción de derechos. Y su limitación por un principio de proporcionalidad absoluta con el hecho cometido es sólo aparente. En efecto, tras la obligada finalización de la medida de seguridad jurídico-penal ex art. 6.2 CP español, si la peligrosidad del sujeto lo hace preciso, la restricción de derechos del mismo puede continuar por la vía del internamiento civil de los incapaces.

4. La pregunta es, entonces, si en el ámbito de los delincuentes imputables la consideración de la peligrosidad carece de todo sentido. Expresado en otros términos, si la estricta medida de la culpabilidad por el hecho define el límite de cualquier intervención restrictiva de derechos (penal o extrapenal) sobre el sujeto. El alejamiento de la legislación española actualmente vigente de cualquier consideración como las reseñadas no debe conducir a engaño. En efecto, existen indicios significativos de que en la sociedad no se comparte la tesis de que la culpabilidad por el hecho ha de definir la frontera absoluta de distribución de riesgos entre individuo y sociedad. Esto es, la

\footnotetext{
41 De hecho, la predelictualidad ya era característica de algunas de las antiguas "Sexual Psycopath Acts" norteamericanas: HORWITZ, UPLR 57 (1995), p. 40 nota 27, 61.

${ }^{42}$ En efecto, el Código de 1995, al acoger incluso en las medidas de seguridad para los delincuentes inimputables el criterio de la proporcionalidad con el hecho cometido (art. 6. 2) y no contemplar siquiera reacciones para delincuentes imputables habituales o peligrosos, se sitúa en las antipodas de cualquier discurso de "peligrosidad" Sin embargo, los autores de referencia del legislador de 1995 admiten que tras el cumplimiento de la medida de seguridad penal los sujetos peligrosos puedan ser sometidos a reacciones civiles ( $y$ cabe imaginar que tampoco tendrian objeciones respecto a reacciones de naturaleza administrativa).
} 
tesis de que, cumplida la condena ajustada a la culpabilidad, la sociedad deba asumir siempre todo el riesgo de un delito futuro cometido por el sujeto imputable. Por el contrario, parece que se admite la idea de que la constatación de una seria peligrosidad subsistente tras el cumplimiento de la condena debería dar lugar a alguna fórmula de aseguramiento cognitivo adicional. Si esta percepción fuera correcta, podría ser sólo cuestión de tiempo que se plantearan -también en España- propuestas de solución radicales, en la línea de lo acontecido en otros países. Por ello, y frente a las posturas autocomplacientes, parece razonable que tenga lugar también entre nosotros una discusión sobre la conveniencia de una reforma controlada y no presidida por criterios de oportunidad, producida, como en el caso alemán o el norteamericano, bajo el impacto emocional de un caso (o una serie de casos) de consecuencias dramáticas.

5. En realidad, algunas de las medidas que parecen necesarias ni siquiera requerirían necesariamente de un cambio legal: bastaría con que los órganos jurisdiccionales - los Jueces de Vigilancia Penitenciaria - aprovecharan la institución de la libertad condicional, para hacer de ella una auténtica libertad "condicional", esto es, sometida al cumplimiento de una serie de reglas de conducta, controlado por el personal adecuado para ello ${ }^{43}$. Expresado de otro modo, que aprovecharan la habilitación legal del art. 90.2 CP ("podrán") para imponer, al decretar la libertad condicional, una o varias de las reglas del art. $105 \mathrm{CP}$.

6. Otras medidas, sin embargo, sí requerirían tal reforma legislativa. Así, por ejemplo, la previsión de algún género de medidas de control de la vida en libertad tras el licenciamiento definitivo del penado. $O$, también, la regulación de medidas de seguridad-como las que reiteradamente ha propuesto entre nosotros Cerezo $\mathrm{Mir}^{44}$ para sujetos habituales o peligrosos, desde luego no sujetas a un principio absoluto de proporcionalidad con el hecho cometido, que las anula antes de empezar, pero tampoco absolutamente indeterminadas, ni siquiera condicionadas a la -discutible- reversión del pronóstico de peligrosidad. Por contra, habría de tratarse de medidas regidas por un criterio de proporcionalidad que determine -valorativamente- el momento en que el riesgo de reincidencia pasa a ser asumido por el conjunto de la sociedad, como parece razonable que tenga lugar en el marco de un Estado de derecho que disponga una distribución equilibrada de cargas entre individuo y sociedad.

7. En realidad, la búsqueda de criterios valorativos de distribución razonable entre individuo y sociedad- de la carga de la inseguridad habría de ser el criterio rector de la reforma. Una reforma que, por tanto, descartaría cualquier concepción radical de

\footnotetext{
43 Aunque una reforma legal en este punto, a fin de distinguir entre clases de delitos y proporcionar una base más precisa a las decisiones judiciales sería más satisfactoria.

44 Últimamente en CEREZO MIR, "Consideraciones político-criminales sobre el proyecto de Código penal de 1992", Lección inaugural del curso académico 1993-1994, Universidad de Zaragoza, pp. 37 y ss.
} 
la inocuización, como distribución desequilibrada de cargas en perjuicio del penado ${ }^{45}$. Pues como señalan, con razón, Schall/ Schreibauer ${ }^{46}$, "una sociedad que quiere mantenerse en un Derecho penal respetuoso con la individualidad y los derechos fundamentales de la persona, también del delincuente, una sociedad que, por tanto, quiere conceder a todo autor la posibilidad de la resocialización, debe también estar dispuesta necesariamente a soportar un riesgo para la seguridad de la colectividad".

\footnotetext{
${ }^{45}$ Una distribución absolutamente desequilibrada de las cargas entre individuo y sociedad es, por ejemplo, la que se contiene en la Jacob Wetterling Act norteamericana, que implica no sólo una afectación de la intimidad o una dificultad añadida a la reinserción, sino incluso un auténtico peligro para la vida o integridad de los excarcelados tras cumplir su condena.

${ }^{46}$ NJW 1997, p. 2420.
} 